\title{
8-Hydroxyqunoline adsorption from aqueous solution using powdered orange peel: kinetic and isotherm study
}

\author{
Khalid SIRAJ, ${ }^{1 *}$ Dema DESO, Demelash JADO, Girma SELALE \\ ${ }^{1}$ Department of Chemistry, College of Natural Sciences, Jimma University, \\ P.O. Box 378, Jimma, Ethiopia \\ e-mail: chemdocprof@gmail.com (*corresponding author)
}

Manuscript received March 305, 2015; revised April 30, 2015; accepted June 02, 2015

\begin{abstract}
Adsorption of 8-hydroxyquinoline (8HQ) on powdered orange peel (POP), a locally available adsorbent, has been studied. Experiment was performed on different 8HQ concentration, particle size, and adsorbent dosage. The Langmuir and Freundlich adsorption isotherm model has been tested. The obtained results best fitted the Langmuir model, suggesting monolayer adsorption of $8 \mathrm{HQ}$ on POP. The kinetic studies for the adsorption process were also carried out using pseudo-first- and pseudo-second-order models, and the data obtained is best fitted to the pseudo-second-order kinetic model. Thermodynamic parameters were calculated for the adsorption process and the result showed that the values of $\Delta \mathrm{G}_{\mathrm{ads}}, \Delta \mathrm{H}_{\mathrm{ads}}$, and $\Delta \mathrm{S}_{\text {ads }}$ are $-1171.4 \mathrm{~J} / \mathrm{mol},-140 \mathrm{~J} / \mathrm{mol}$ and $-40.5 \mathrm{~J} / \mathrm{K}$ at $303 \mathrm{~K}$. Thus, it can be summarized that the adsorption of $8 \mathrm{HQ}$ is spontaneous, chemisorbed, monolayer, and exothermic
\end{abstract}

Keywords: adsorption, 8-hydroxyquinoline, orange peel, isotherm model

\section{Introduction}

Water resources including fresh water are of great importance for natural ecosystems as well as human development, but they are becoming limited due to the increasing population, urbanization, and climate changes. This scarcity is basically due to water pollution, which is caused by the discharge of untreated or partially treated industrial effluents into the natural ecosystem, posing serious problems to it. Thus, these industrial effluents, containing a number of organic and inorganic chemicals, such as phenols, formaldehyde, 8-hydroxyquinoline, dyes, and heavy metals, are major water pollutants [1]. 
8-hydroxyquinoline is an organic compound with the formula $\mathrm{C}_{9} \mathrm{H}_{7} \mathrm{NO}$. It is a derivative of the heterocycle quinoline by placement of an $\mathrm{OH}$ group on carbon number 8 . This light yellow compound is widely used commercially, although under a variety of names $[2,3]$. Heterocyclic aromatic hydrocarbons containing $\mathrm{N}$, $\mathrm{S}$, or $\mathrm{O}$ in the ring structure are one of the common contaminants of ground-water originating from coal gasification and oil refining processes, wood treatment processes, forest fires, automobile exhaust, and disposal of fuels and oils. Many of these compounds are reported to be toxic, carcinogenic, and they tend to accumulate in aquatic organisms even when present in low concentrations. Also the presence of the hetero atom makes them more soluble than their homo-cyclic analogues [4-7]. They are also used as preservatives in cosmetics and tobacco, chemical intermediates in dye synthesis as well as sophomoric and organometallic indicators, besides their wide usage [8].

8HQ and its derivatives should be removed from waste waters due to their toxic and harmful effects on aquatic organisms and human health. Several methods for treating organic pollutants from waste waters, such as precipitation, solvent extraction, or adsorption, can be used. Adsorption is one of the respective methods for waste water treatment due to its several advantages such as high efficiency, low-cost, simple application, and easy recovery of the adsorbent [9-11].

This work has been designed to remove $8 \mathrm{HQ}$ from aqueous solution through adsorption using orange peel powder as an adsorbent.

\section{Material and method}

The following chemicals were used for this study: hydrochloric acid, $\mathrm{NaOH}$ (BDH, England), and 8-hydroxyqunoline (98\% sigma Aldrich) used for preparing the standard solution for the adsorption process. Orange peels were collected from Jimma town cafeterias to use as adsorbent material for the removal of 8 HQ from the aqueous solution. Distilled water and deionized water were used to prepare the standard stock solution. Analytical balance, Oven, Sieve $(150 \mu \mathrm{m}), \mathrm{pH}$ meter (pH211, HANNA), and UV-visible spectrophotometer (JENWAY 6705) were used in this work.

\section{Adsorbent from orange peel}

The adsorbent material, orange peel, was collected and washed with tap water followed by drying in the sun and chopping. The chopped orange peel is powdered and then washed with distilled water until its $\mathrm{pH}$ reaches 7 and is dried in the oven. 
Preparation of the stock solution

$0.1 \mathrm{M}$ of stock solution was prepared; by weight: $14.56 \mathrm{~g}$ of 8-HQ into $1 \mathrm{~L}$ of hot water. Five standard solutions, $(0.05 \mathrm{M}, 0.025 \mathrm{M}, 0.0125 \mathrm{M}, 0.00625 \mathrm{M}$, and $0.00325 \mathrm{M}$ ) were prepared by diluting hot water. 0.5 gm powdered orange peel was weighted and added into five shaking bottles, and followed by the addition of 25 $\mathrm{ml}(0.05 \mathrm{M}, 0.025 \mathrm{M}, 0.0125 \mathrm{M}, 0.00625 \mathrm{M}$, and $0.00325 \mathrm{M})$ in each of the five shaking bottles. Then the sample is shaken for 30 minutes and filtered using filter paper. The filtered sample is analysed by UV-Vis spectrophotometer at $325 \mathrm{~nm}$.

\section{Adsorption isotherm}

In a solid-liquid system, adsorption results in the removal of solutes from solution and their accumulation at solid surface. The solute remaining in the solution reaches a dynamic equilibrium with that adsorbed on the solid phase. The amount of adsorbate that can be taken up by an adsorbent as a function of both temperature and concentration of adsorbate, and the process, at constant temperature, can be described by an adsorption isotherm according to the general Eq. (1): in this study, the extent of phenolic compounds adsorption capacity at equilibrium, $q_{e}(\mu \mathrm{g} / \mathrm{g})$, was calculated:

$$
\begin{aligned}
& q_{e}=\frac{\left(C_{o}-C_{e}\right) V}{W} \\
& q_{t}=\frac{\left(C_{o}-C_{t}\right) V}{W}
\end{aligned}
$$

The percentage of phenolic compounds removal was calculated using Eq. (3):

$$
\text { (\%)Adsorption }=\frac{C_{o}-C_{e}}{C_{o}} \times 100
$$

$C_{0}$ corresponds to the initial concentration of 8-HQ compounds and $C_{\mathrm{e}}(\mu \mathrm{g} / \mathrm{g})$ corresponds to the concentration of phenolic compounds at equilibrium. $V(\mathrm{~L})$ is the volume of the solution and $W(\mathrm{~g})$ is the mass of the dry adsorbent.

\section{Result and discussion}

\section{Calibration of 8-hydroxyquinoline}

A calibration curve was composed of a minimum of a blank and three standards. A calibration curve was made for every hour of continuous sample analysis. More concentrated samples were diluted and the standard was falling on the plateau of a calibration curve - Fig. 1 . 

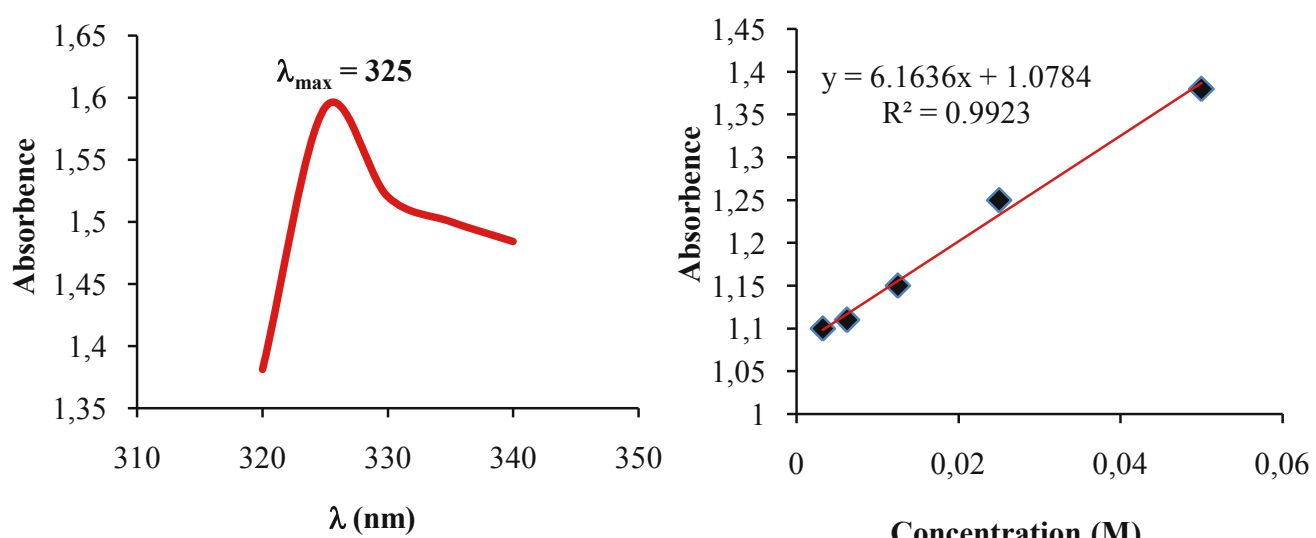

Concentration (M)

Figure 1. Calibration of 8-hydroxyquinoline in aqueous solution.

Adsorption isotherm study

Adsorption isotherm is a basic requirement for the design of an adsorption system. The adsorption mechanism was investigated using Langmuir and Freundlich models. The two models differ from each other in their assumption concerning the existence of fine adsorption capacity [12].

The Langmuir isotherm describes quantitatively the formation of monolayer on the outer surface of the adsorbent, and after that no further adsorption takes place - Fig. 2. The Langmuir isotherm is valid for monolayer adsorptions onto the surface containing a fine numbers of identical sites $[13,14]$.

The linear form of the Langmuir isotherm is given by the following equation:

$$
\frac{1}{q_{e}}=\frac{1}{C_{e} q_{m} b_{L}}+\frac{1}{q_{m}}
$$

where $\mathrm{q}_{\mathrm{e}}$ and $\mathrm{q}_{\max }$ are equilibrium and maximum uptake capacity $(\mathrm{mg} / \mathrm{g})$, respectively; $b_{L}$ is related to the free energy of adsorption and representing the Langmuir adsorption constant $\mathrm{C}_{\mathrm{eq}}$ is the equilibrium adsorbate concentration in molarity.

The Langmuir constant which is related to the maximum capacity $\left(\mathrm{q}_{\max }\right)$ and energy adsorption $\left(b_{1}\right)$ can be calculated from the slope of linear plot $1 / \mathrm{q}_{\mathrm{eq}}$ versus $1 / \mathrm{C}_{\mathrm{eq}}$ as straight line.

The essential characteristics of the Langmuir equation can be expressed in terms of a dimensionless factor, $\mathrm{R}_{\mathrm{L}}$, which is given (Table 1) by

$$
R_{L}=\frac{1}{1+b_{L} C_{O}}
$$


where $b_{L}$ is the Langmuir constant and $C_{0}$ is the initial concentration of the adsorbate in solution. The values of $\mathrm{R}_{\mathrm{L}}$ indicates the type of isotherm to be irreversible $\left(\mathrm{R}_{\mathrm{L}}=0\right)$, favourable $\left(0<\mathrm{R}_{\mathrm{L}}<1\right)$, linear $\left(\mathrm{R}_{\mathrm{L}}=1\right)$, or unfavourable $\left(\mathrm{R}_{\mathrm{L}}>1\right)$. The value of $\mathrm{R}_{\mathrm{L}}$ is found to be $0.897 \mathrm{mg} / \mathrm{L}$ at $303 \mathrm{~K}$, indicating that the adsorption of phenol is favourable on the powdered orange peel.

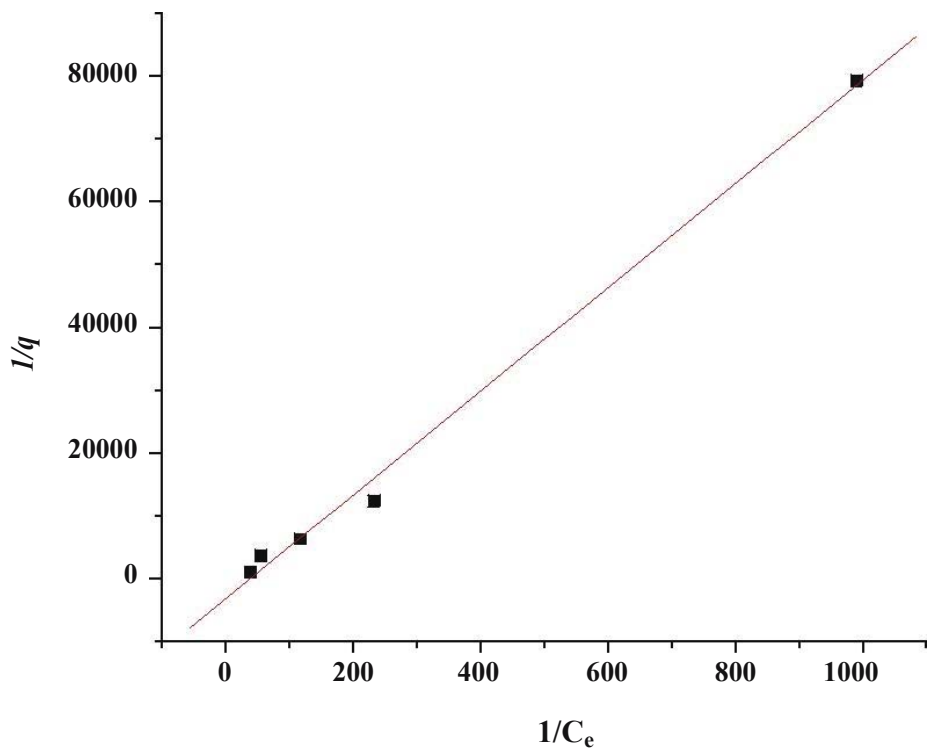

Figure 2.Isotherm model for the adsorption of the 8-hydroxyquinoline Langmuir model

The Freundlich adsorption isotherm is commonly used to describe the characteristic for the heterogamous surface. The linear form of the Freundlich is given in the following equation (Fig. 3).

$$
\log q_{e}=\log K_{F}+\frac{1}{n} \log C_{e}
$$

where $\mathrm{K}_{\mathrm{f}}$ is an approximate indicator of adsorption capacity, while is function of the strength of adsorption in the sorption process and the smaller $1 / \mathrm{n}$ is the greater expected heterogeneity (d). $\mathrm{n}$ is lies between 1 to 10 this indicates a favourable adsorption process [15]. 


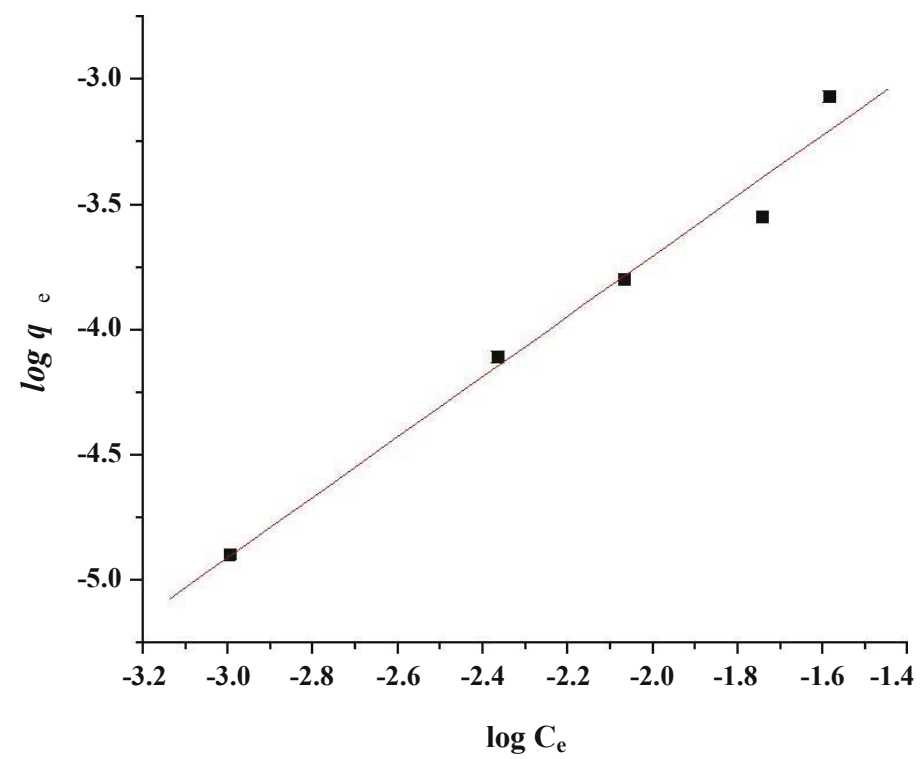

Figure 3. Isotherm model for the adsorption of the 8-hydroxyquinoline Freundlich model

From Table 1 , the value of $1 / \mathrm{n}=1.2$ and the value of $\mathrm{R}^{2}$ is 0.988 . Freundlich's model investigated adsorption capacity $\mathrm{K}_{\mathrm{f}}$ and adsorption capacity $(1 / \mathrm{n}) . \mathrm{K}_{\mathrm{f}}$ intercept is $0.05 \mathrm{mg} / \mathrm{g}$, showing appreciable affinity for the 8 -hydroxyquinoline adsorption; the value of $\mathrm{n}$ ranging from 1 to 10 shows a favourable adsorption. The correlation coefficient value is 0.988 and it shows that the Freundlich model is not applicable to equilibrium as compared to linear Langmuir models $\left(\mathrm{R}^{2}=0.997\right)$, which indicate monolayer formation on the surface of the adsorbent.

Table 1. Isotherm parameters for 8-hydroxyquinoline adsorption on orange peel adsorbent

\begin{tabular}{cl}
\hline Adsorption isotherm \& constants & Values \\
\hline Langmuir & \\
\hline $\mathrm{q}_{\mathrm{m}}(\mathrm{mg} / \mathrm{g})$ & 0.012 \\
$\mathrm{~b}_{\mathrm{L}}\left(\mathrm{L} \cdot \mathrm{mg}^{-1}\right)$ & -0.027 \\
$\mathrm{R}^{2}$ & 0.997 \\
$\mathrm{R}_{\mathrm{L}}(\mathrm{mg} / \mathrm{L})$ & 0.897 \\
\hline Freundlich & \\
\hline $1 / \mathrm{n}$ & 1.205 \\
$\mathrm{~K}_{\mathrm{f}}$ & 0.051 \\
$\mathrm{R}^{2}$ & 0.988 \\
\hline
\end{tabular}




\section{Adsorption kinetics}

Adsorption kinetics is significant in evaluating the performance of a given adsorbent and in getting an insight into the rate of adsorption and the rate-limiting step of the transport mechanism, which is primarily used in the modelling and design of the adsorption process. In order to evaluate the kinetics parameters, pseudo-first-order and pseudo-second-order equations were implemented to analyse the experimental data. The pseudo-first-order equation can expressed as

$$
\log \left(q_{e}-q_{t}\right)=\log q_{e}-\frac{k_{1}}{2.303} t
$$

where $\mathrm{q}_{\mathrm{e}}$ and $\mathrm{q}_{\mathrm{t}}$ are the amount of adsorbate in $\mathrm{mg}$ at equilibrium at any time $\mathrm{t}$, while $\mathrm{k}_{1}$ is the first-order rate constant $\left(\mathrm{min}^{-1}\right)$.

From the plot of $\log \left(\mathrm{q}_{\mathrm{e}}-\mathrm{q}_{\mathrm{t}}\right)$ versus $\mathrm{t}$, in Figure 4, $\mathrm{k}_{1}$ can be calculated from the slope and theoretical $\mathrm{q}_{\mathrm{e}}$ can be obtained from the intercept.

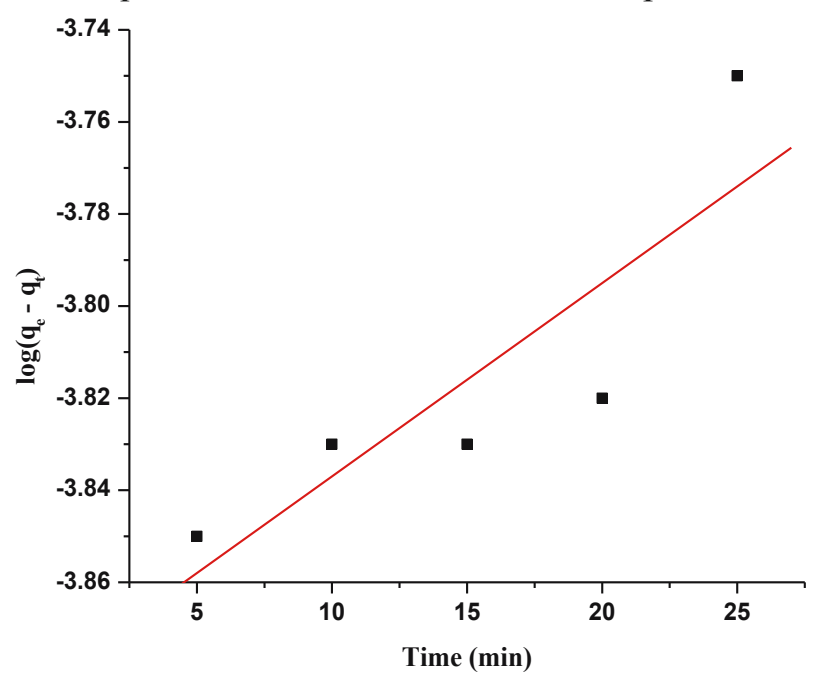

Figure 4. Pseudo-first-order kinetic model for 8-hydroxyquinoline adsorption on powdered orange peel

The pseudo-second-order equation is expressed as follows:

$$
\frac{t}{q_{t}}=\frac{1}{k_{2} q_{e}^{2}}+\frac{1}{q_{e}} t
$$


where $\mathrm{k}_{2}$ is rate constant of second-order adsorption. The linear plot of $\frac{t}{q_{t}}$ versus time gives $\frac{1}{q_{e}}$ as slope and $\frac{1}{k_{2} q_{e}^{2}}$ as intercept - Fig.5.

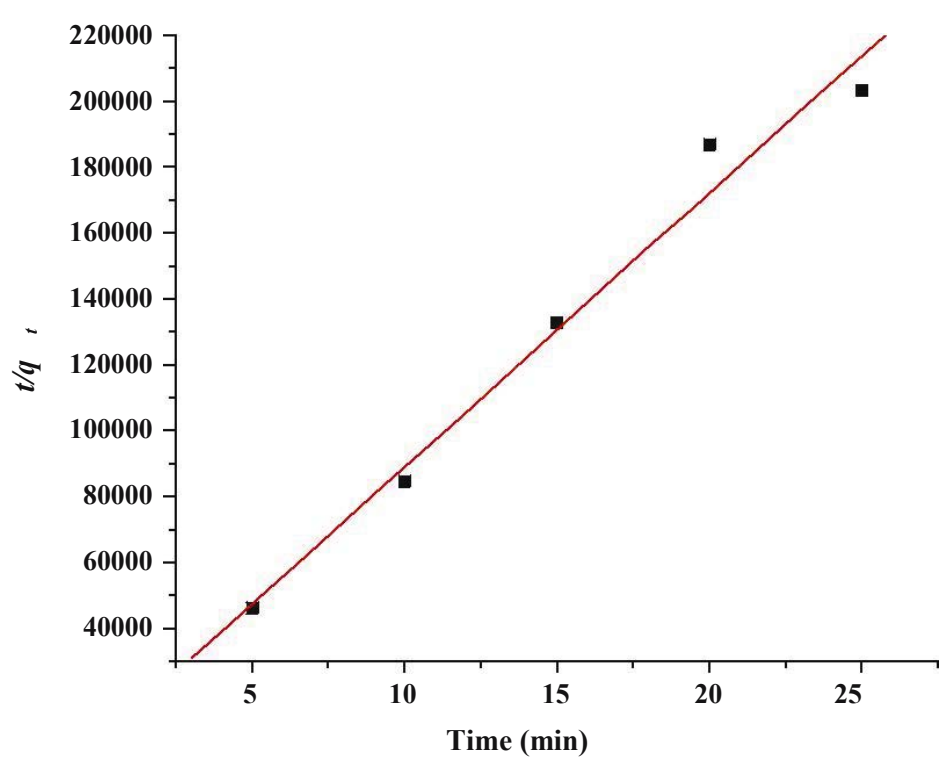

Fig. 5. Pseudo-second-order kinetic model for 8-hydroxyquinoline adsorption on powdered orange peel

The adsorption of 8-HQ onto orange peel shows a rapid initial adsorption rate followed by a slower rate. Initially, adsorption sites are abundantly available and 8HQ interacts easily; hence, a higher rate of adsorption was observed. However, after the initial periods, the lower adsorption may be due to the slower diffusion of adsorbate into the interior adsorbent. The two adsorption kinetics models mentioned above have been used to understand the adsorption kinematics and correlation coefficient, $\mathrm{R}^{2}$, where calculated from plots. The linearity of those plots indicates the capacity of the two models. The correlation coefficient adsorption kinematics is 0.863 and 0.990 for pseudo-first-order and second-order, respectively. The correlation coefficient shows that the pseudo-second-order models fit better to the experimental data than the pseudo-first-order models. The obtained constants for the pseudo-first- and pseudo-second-order kinetics model are tabulated in Table 2. 
Tab. 2. Kinetics parameters for the adsorption of 8-hydroxyquiniline from aqueous solution

\begin{tabular}{cc}
\hline Kinetic models \&constants & Values \\
\hline Pseudo-first-order & \\
\hline $\mathrm{q}_{\mathrm{e}}$ cal. $(\mathrm{mg} / \mathrm{g})$ & $1.32 \mathrm{E}-04$ \\
$\mathrm{k}_{1}\left(\mathrm{~min}^{-1}\right)$ & 0.0096 \\
$\mathrm{R}^{2}$ & 0.863 \\
\hline Pseudo-second-order & \\
\hline qecal. (mg/g) & $1.20 \mathrm{E}-04$ \\
$\mathrm{k}_{2}(\mathrm{~L} / \mathrm{mg} . \mathrm{min})$ & $11,607.08$ \\
$\mathrm{R}^{2}$ & 0.990 \\
\hline
\end{tabular}

\section{Adsorption thermodynamics}

In order to fully understand the nature of adsorption, the thermodynamics parameters such as the standard Gibbs free energy, the standard entropy, or the standard change in enthalpy can be calculated using the following equation:

$$
\Delta G^{O}=-R T \ln K_{c}
$$

where the gas constant $(8.3145 \mathrm{~J} / \mathrm{mol} . \mathrm{K})$ is the absolute temperature in Kelvin and $\mathrm{K}_{\mathrm{c}}$ is the standard thermodynamic equilibrium constant defined by $\mathrm{C}_{\mathrm{o}} / \mathrm{C}_{\mathrm{e}}$, and the temperature change from 303 to $313 \mathrm{~K}$ was computed from the following equation:

$$
\ln K_{c}=\frac{\Delta S^{O}}{R}-\frac{\Delta \mathrm{H}^{O}}{R T}
$$

$\Delta \mathrm{H}(\mathrm{kJ} / \mathrm{mol})$ and $\Delta \mathrm{S}(\mathrm{kJ} / \mathrm{mol})$ were calculated from the slope and the intercept of linear plot of $\operatorname{lnK}_{\mathrm{c}}$ vs $1 / \mathrm{T}$. Enthalpy change $(\Delta \mathrm{H})$ is used to identify whether the adsorption process is exothermic or endothermic, but the standard entropy change determines the disorders of adsorption at solid-liquid interface [16]. The thermodynamic parameters of adsorption where calculated using equations (9) and (10); the calculated value of these parameters are given in Table 3.

Table 3. Thermodynamic parameters for the adsorption of 8-hydroxyquiniline from aqueous solution

\begin{tabular}{ccccc}
\hline $\mathbf{T}(\mathbf{K})$ & $\operatorname{lnKc}$ & $\Delta \mathbf{G}_{\text {ads }}(\mathbf{J} / \mathbf{m o l})$ & $\Delta \mathbf{H}_{\text {ads }}(\mathbf{J} / \mathbf{m o l})$ & $\Delta \mathbf{S}_{\text {ads }}(\mathbf{J} / \mathbf{m o l})$ \\
\hline 303 & 0.465 & -1171.4 & & \\
308 & 0.444 & -1136.9 & -140 & -40.485 \\
313 & 0.339 & -882.2 & & \\
\hline
\end{tabular}

The negative values of enthalpy confirm that the exothermic nature of the adsorptions process and $-140(\mathrm{~J} / \mathrm{mol})$ amount of heat is released during the binding 
of 8-hydroxyquiniline on the surface of orange peel. The negative value of entropy indicates decreasing randomness at solid-liquid interface during adsorption. The negative values of $\Delta \mathrm{G}$ confirm that the adsorption process is spontaneous, which becomes a less negative value with an increasing temperature, indicating that adsorption occurred at a lower temperature.

\section{Conclusion}

8HQ can be removed effectively on powdered orange peel. Batch adsorption was applied and the result revealed that the equilibrium adsorption was attained at 30 minutes. The adsorption isotherm can be well described with the Langmuir model within the studied conditions. Results of kinetics study indicate that the pseudo-second-order kinetics can simulate the adsorption process with a high accuracy for the adsorption of $8 \mathrm{HQ}$ from aqueous solution. Thermodynamic parameters for adsorption, such as $\Delta \mathrm{H}^{\circ}, \Delta \mathrm{S}^{\circ}$, and $\Delta \mathrm{G}^{\circ}$, were calculated for the adsorption process, and the result showed that the free energy, enthalpy, and entropy of adsorption were $-1171.4 \mathrm{~J} / \mathrm{mol},-140 \mathrm{~J} / \mathrm{mol}$, and $-40.485 \mathrm{~J} / \mathrm{mol}$ at $303 \mathrm{~K}$, respectively. This indicates that the adsorptions of $8 \mathrm{HQ}$ are spontaneous, chemisorbed, mono-layered, and exothermic.

\section{Acknowledgement}

We thankfully acknowledge to the Department of Chemistry, College of Natural Sciences, Jimma University, Ethiopia for providing the necessary facilities for carrying out this work.

\section{References}

[1] Are-llano-Cárdenas, S., Gallardo-Velazquez, T., Osorio-Revilla, G., López-Cortéz, Ma. Del S., Gómez-Perea, B. (2005), Adsorption of phenol and dichlorophenols from aqueous solutions by porous clay heterostructure (PCH) J. Mex. Chem. Soc. 49, 287-291.

[2] "8-Hydroxyquinoline Safety Data". Oxford University.

[3] "8-Hydroxyquinoline". PAN Pesticides Database.

[4] Bayona, J. M., Sabaté, J., Solanas, A. M. (2001), Photolysis of PAHs in aqueous phase by UV irradiation. Chromosphere 44, 119-124.

[5] Shemer, H., Linden, K. G. (2007), Aqueous photodegradation and toxicity of the polyclinic aromatic hydro car bones fluorine, dibenzofuran, and dibenzothiophene. Water Res. 41, 853861.

[6] Broholm, E., Arvin, M. (1999), Sorption of heterocyclic compounds on natural clayey till. $J$. Contam. Hydrol. 39(3-4), 183-200.

[7] Meyer, S., Cartellieri, S., Steinhart, H. (1999), Simultaneous determination of PAHs, hetero PAHs (N, S, and O), and their degradation products in creosote-contaminated soils: method development, validation, and application to hazardous waste sites. Anal. Chem. 71, 4023-4029. 
[8] Shchavlev, A. E., Pankratov, A. N., Shalabay, A. V. (2006), DFT computational studies on rotation barriers, tautomerism, intra-molecular hydrogen bond, and solvent effects in 8hydroxyquinoline. Int. J. Quant. Chem. 106, 876-886.

[9] Ali A. I. Abdul Zahra (2011), Synthesis, characterization and spectroscopic properties of new azo-dyes and azo-metal complexes derived from 8-hydroxyquinoline. Basrah Journal of Science(C) 28, 15-36.

[10] Özcan, A. S., Erdem, B., Özcan, A. (2005), Adsorption of Acid Blue 193 from aqueous solutions onto BTMA-bentonite. Colloids Surf. A: Physiochemical. Eng. Aspects 266, 73-81.

[11] Seungman, S., Dongsu, K. (2005), Modification of Langmuir isotherm in solution systems definition and utilization of concentration dependent factor. Chemosphere 58, 115-123.

[12] Metcalf, E. (1991), Wastewater engineering: treatment, disposal and reuse. McGraw-Hill, New York; $3^{\text {rd }}$ Edition, 364-449.

[13] Gercel, O., Gercel, H. F. (2007), Adsorption of lead (II) ions from aqueous solutions by activated carbon prepared from biomass plant material of Euphorbia rigida. Chemical Engineering Journal 132, 289-297.

[14] Voudrias, D. E., Fytianos, F., Bozani, E. (2002), Sorption description isotherm of dyes from aqueous solutions and waste waters with different sorbet material. Global Nest: The Int. J. 4, $75-78$.

[15] Golderg, S. (2005), Equations and models describing adsorption processes in soils. Chemical processes in soil, SSSA Book Series 8. Soil Science Society of America, 677Ss. Segoe Road, Madison, WI53711, USA.

[16] Kumar, A. S. K., Kalidhasan, S., Rajesh, V., Rajesh, N. (2012), Application of cellulose-clay composite biosorbent toward the effective adsorption and removal of chromium from industrial wastewater. Ind. Eng. Chem. Res. 51, 58-69. 